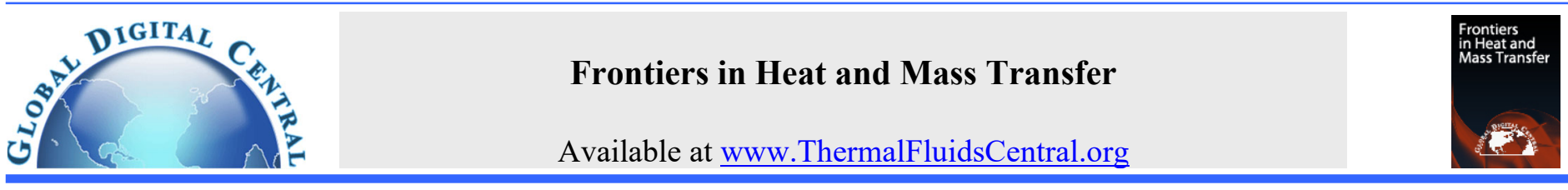

\title{
A NUMERICAL ANALYSIS ON THE EFFECT OF DEVIATION FROM A CENTERED WICK STRUCTURE IN AN ULTRA-THIN FLATTENED HEAT PIPE
}

\author{
Yasushi Koito ${ }^{\mathrm{a}, *}$ \\ ${ }^{a}$ Kumamoto University, Kumamoto-shi, Kumamoto, 860-8555, Japan
}

\begin{abstract}
For ultra-thin heat pipes, a centered wick structure is often used. In this study, a numerical analysis is performed on an ultra-thin heat pipe in which the wick structure's position has deviated from the center. A 3D heat pipe model, developed by the author in a previous study, is extended, and numerical calculations are conducted to determine any differences in performance because of an off-center wick. The major findings are as follows: (1) a completely centered wick structure is recommended for optimum performance; (2) accurate central positioning of the wick structure is important in the fabrication process of ultra-thin heat pipes.
\end{abstract}

Keywords: heat transfer, thermal design, ultra-thin heat pipe, centered wick structure, deviation

\section{INTRODUCTION}

Many research studies have been conducted on heat pipes (e.g., Faghri, 2016; Sohel Murshed and Nieto de Castro, 2017; Mochizuki and Nguyen, 2019; Sobhan and Peterson, 2019; Guo et al., 2020). Among them, in recent years, an attention has been paid on ultra-thin heat pipes for thermal management of thin electronics devices. Recently, Shi et al. (2019) fabricated an 80-mm-long, 50-mm-wide, and 0.65-mm-thick ultra-thin heat pipe. The height of the vapor flow channel within the heat pipe was $0.2 \mathrm{~mm}$. The heat pipe's effective thermal conductivity was 800 $\mathrm{W} /(\mathrm{m} \cdot \mathrm{K})$ under a power input of $15.9 \mathrm{~W}$, evaporator section temperature of $60^{\circ} \mathrm{C}$, and a vertical orientation mode. Tang et al. (2019) examined the thermal performance of ultra-thin heat pipes with mesh wicks in various structures. The length, width, and thickness of the heat pipe was 150, 8.5, and $1.0 \mathrm{~mm}$, respectively. Zhou et al. (2019) developed an ultra-thin heat pipe of $120 \times 9 \times 0.75 \mathrm{~mm}$ with a centered wick structure. The height of the vapor flow channel was $0.35 \mathrm{~mm}$. Their experiments compared different widths of the wick structure. Li et al. (2019) fabricated an ultrathin heat pipe of $100 \times 50 \times 0.5 \mathrm{~mm}$. The effective thermal conductivity of $2.88 \times 10^{4} \mathrm{~W} /(\mathrm{m} \cdot \mathrm{K})$ was then obtained at a power input of $7.37 \mathrm{~W}$. All the abovementioned studies used a capillary wick structure to circulate a working fluid within their ultra-thin heat pipes. Furthermore, the selfexcited oscillation phenomena of a working fluid were used for fabricating ultra-thin heat pipes. Liu et al. (2019) conducted simultaneous visual and thermal investigations to better understand the thermo-hydrodynamic characteristics of a micro oscillating heat pipe. Their heat pipe had a five-turn meandering rectangular channel with a hydraulic diameter of $550 \mu \mathrm{m}$. The other recent studies on ultra-thin heat pipes were reviewed in the author's previous papers (Koito, 2019a; Koito, 2019b). Usually, ultra-thin heat pipes are used in the thermal management of smartphones. However, they are also used in proton exchange membrane fuel cell stacks (Luo et al., 2020) and solar collectors in a solar energy system (Zhong et al., 2020).
A flattening technique is a typical approach, i.e., a capillary wick structure is inserted within a metal circular pipe, which is finished by flattening the pipe to a desired thickness, to fabricate an ultra-thin heat pipe. The wick structure is positioned at the center. Vapor flow spaces are retained on both sides of the wick structure (Fig. 1). This inner structure is very different from that of a conventional capillary-driven heat pipe of normal size in which a wick structure is attached to the inner wall of the heat pipe container (Sadeghinezhad et al., 2016; Tharayil et al., 2017; Naemsai et al., 2019). The vapor flow channel of an ultra-thin heat pipe is extremely narrow; thus, it is vital to consider the effects of vapor flow friction in the thermal design process of ultra-thin heat pipes (Koito, 2019a).

As mentioned previously, flattening technique is used in fabricating ultra-thin heat pipes. However, it requires accurate positioning of the wick structure; otherwise, its position may deviate from the center of the heat pipe. Because the effect of vapor flow friction can be considerable, it is recognized that any wick structure deviation from the center would influence the thermal performance of the heat pipe. Even for a small deviation, the effect would be considerable because of the narrowness of the vapor flow channel. Thus, for rational thermal design and fabrication of ultra-thin heat pipes, quantitative information concerning deviation effects is required.

In this study, therefore, numerical analyses were conducted to investigate the thermal-fluid transport characteristics of ultra-thin heat pipes in which the position of the wick structure had deviated from the center. To date, although many experimental research studies have been conducted on ultra-thin heat pipes, the deviation effect has not been clarified. A mathematical model developed by the author (Koito, 2019a) was extended to consider the deviation. Figures for the velocity, pressure, and temperature distributions within the ultra-thin heat pipe were obtained for different positions of the wick structure, including where it was positioned at the side of the vapor flow channel. 


\section{MATHEMATICAL MODEL AND NUMERICAL CONDITIONS}

Figure 1 shows a cross-section of an ultra-thin heat pipe; it is perpendicular to a heat transport direction from an evaporator to a condenser section. This study's numerical analyses considered an ultrathin heat pipe in which the position of a wick structure had deviated from the center of the heat pipe. As shown by the dotted lines in Fig. 1, a computational domain included two vapor flow channels and a wick structure between them. The deviation, $\delta$, was then defined by the difference between the centers of the wick structure and the heat pipe container. Figure 2 shows a 3D mathematical model of the ultra-thin heat pipe. The heat pipe model comprised two vapor regions ( $\mathrm{V}_{\mathrm{I}}$ region and $\mathrm{V}_{\text {II }}$ region) and a liquid-wick region (L region). These three regions had the same total length, $l_{t}$, and height, $h$. The widths of $\mathrm{V}_{\mathrm{I}}, \mathrm{V}_{\mathrm{II}}$, and $\mathrm{L}$ regions are denoted by $w_{v, \mathrm{I}}, w_{v, \mathrm{II}}$, and $w_{l}$, respectively. The abovementioned deviation, $\delta$, was then calculated by

$\delta=\frac{w_{v, \mathrm{I}}-w_{v, \mathrm{II}}}{2}$

The governing equations and boundary conditions presented in the author's previous papers (Koito, 2019a; Koito, 2019b) were applied to the present heat pipe mode; therefore, only the main features are described below. The following assumptions were applied to the mathematical model:

a) Steady state is established within the model

b) Vapor flow is laminar

c) Wick structure is isotropic and filled with a working fluid

d) Liquid evaporates and vapor condenses only at two interfaces between the vapor and liquid-wick regions

For three regions: $\mathrm{V}_{\mathrm{I}}(i=v, \mathrm{I}), \mathrm{V}_{\mathrm{II}}(i=v, \mathrm{II})$, and $\mathrm{L}(i=l)$, the governing equations were expressed as follows:

$\nabla \cdot V_{i}=0$

$\rho_{i} \boldsymbol{V}_{\boldsymbol{i}} \cdot \nabla \boldsymbol{V}_{\boldsymbol{i}}=-\nabla p_{i}+\mu_{i} \nabla^{2} \boldsymbol{V}_{\boldsymbol{i}}+\left\{\begin{array}{cl}0 & \text { for } \mathrm{V}_{\mathrm{I}} \text { and } \mathrm{V}_{\text {II }} \text { regions } \\ -\varepsilon \mu_{l} \boldsymbol{V}_{l} / K & \text { for L region }\end{array}\right.$

$\rho_{i} c_{p, i} \boldsymbol{V}_{\boldsymbol{i}} \cdot \nabla T_{i}=\left\{\begin{array}{cl}k_{v, \mathrm{I}} \nabla^{2} T_{v, \mathrm{I}} & \text { for } \mathrm{V}_{\mathrm{I}} \text { region } \\ k_{v, \mathrm{II}} \nabla^{2} T_{v, \mathrm{II}} & \text { for } \mathrm{V}_{\mathrm{II}} \text { region } \\ \left(k_{e f f} / \varepsilon\right) \nabla^{2} T_{l} & \text { for L region }\end{array}\right.$

where $\boldsymbol{V}$ is the velocity vector $(=(u, v, w)), p$ is the pressure, $T$ is the temperature, $\rho$ is the density, $\mu$ is the viscosity, $\varepsilon$ is the porosity, $K$ is the permeability, $c_{p}$ is the specific heat at constant pressure, $k$ is the thermal conductivity, and $k_{\text {eff }}$ is the effective thermal conductivity.

One end (length: $l_{h}$, width: $w_{l}$ ) of the bottom surface of the L region was heated at prescribed heat flux, $q$, whereas the other end (length: $l_{c}$, width: $w_{l}$ ) was cooled. The boundary conditions at the heated and cooled sections are given by the following equations:

$u_{l}=v_{l}=w_{l}=0, \quad-k_{\text {eff }} \frac{\partial T_{l}}{\partial z}=q \quad$ at heated section

$u_{l}=v_{l}=w_{l}=0, \quad-k_{\text {eff }} \frac{\partial T_{l}}{\partial z}=-q \frac{l_{h}}{l_{c}} \quad$ at cooled section

The present heat pipe model had two vapor-liquid interfaces, which were located at $x=w_{v, \mathrm{I}}$ and $w_{v, \mathrm{I}}+w_{l}$, respectively. Using the ClausiusClapeyron equation, the temperatures at these interfaces were calculated by

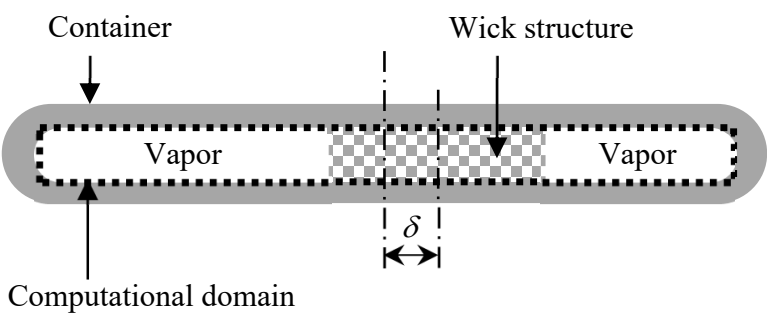

Fig. 1 Computational domain.

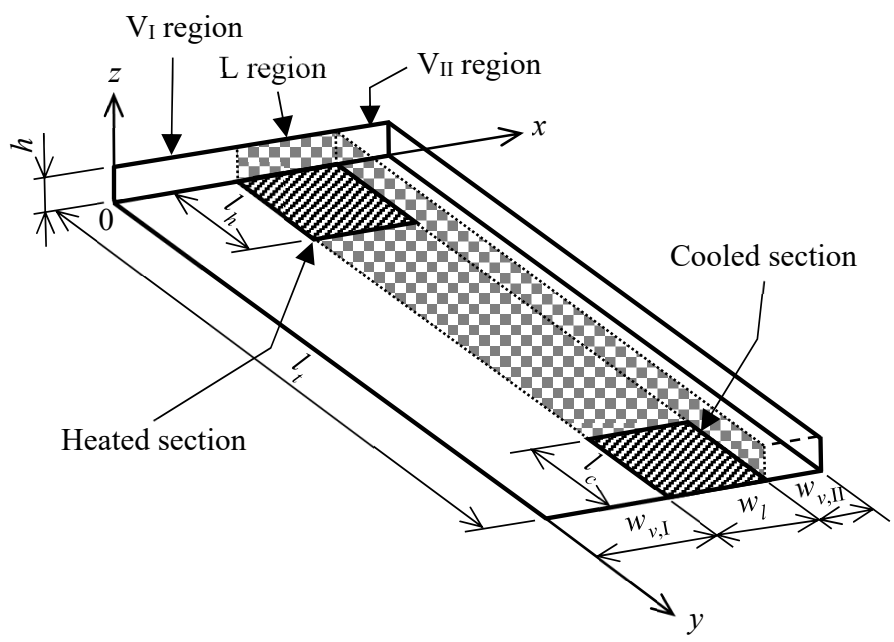

Fig. 2 Mathematical model.

Table 1 Numerical conditions.

\begin{tabular}{|l|l|}
\hline Length of $\mathrm{V}_{\mathrm{I}}, \mathrm{V}_{\mathrm{II}}$, and L regions, $l_{t}[\mathrm{~mm}]$ & 100 \\
\hline Length of heated section, $l_{h}[\mathrm{~mm}]$ & 10 \\
\hline Length of cooled section, $l_{c}[\mathrm{~mm}]$ & 10 \\
\hline Total width of $\mathrm{V}_{\mathrm{I}}, \mathrm{V}_{\mathrm{II}}$, and L regions, $w_{v, \mathrm{I}}+w_{l}+w_{v, \mathrm{II}}[\mathrm{mm}]$ & 3.0 \\
\hline Width of L region, $w l[\mathrm{~mm}]$ & 1.0 \\
\hline Heat flux at heated section, $q\left[\mathrm{~W} / \mathrm{cm}^{2}\right]$ & 20 \\
\hline Operating temperature, $T_{o}\left[{ }^{\circ} \mathrm{C}\right]$ & 50 \\
\hline
\end{tabular}

$T_{v, \mathrm{I}}=T_{l}=\left(\frac{1}{T_{\text {ref }}}-\frac{R_{g}}{h_{f g}} \ln \frac{p_{v, \mathrm{I}}}{p_{\text {ref }}}\right)^{-1} \quad$ at $\quad x=w_{v, \mathrm{I}}$

$T_{v, \mathrm{II}}=T_{l}=\left(\frac{1}{T_{\text {ref }}}-\frac{R_{g}}{h_{f g}} \ln \frac{p_{v, \mathrm{II}}}{p_{\text {ref }}}\right)^{-1} \quad$ at $\quad x=w_{v, \mathrm{I}}+w_{l}$

where $T_{r e f}$ is the reference temperature, $p_{r e f}$ is the reference pressure, $R_{g}$ is the gas constant, and $h_{f g}$ is the latent heat. The vapor and liquid velocities at these vapor-liquid interfaces were calculated from the following equations:

$$
\begin{aligned}
& \rho_{v} h_{f g} u_{v, \mathrm{I}}=\rho_{l} h_{f g} u_{l}=-k_{e f f}\left(\frac{\partial T_{l}}{\partial x}\right) \\
& v_{v, \mathrm{I}}=v_{l}=0, \quad w_{v, \mathrm{I}}=w_{l}=0
\end{aligned}
$$




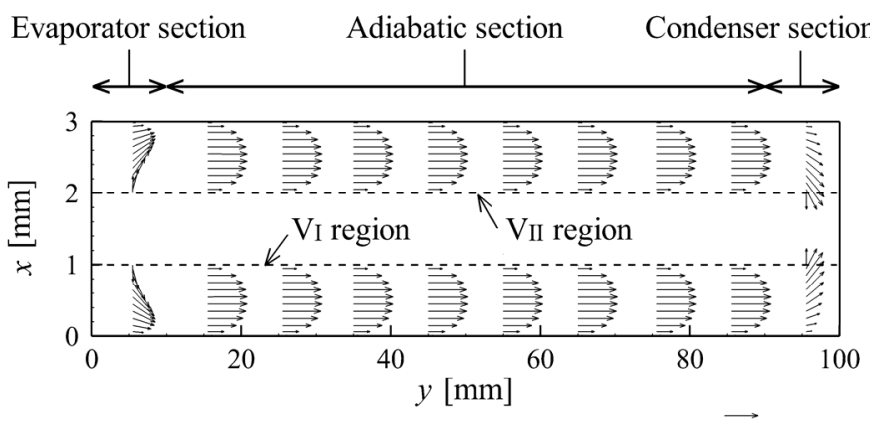

$20 \mathrm{~m} / \mathrm{s}$

(a) $\delta=0 \mathrm{~mm}$

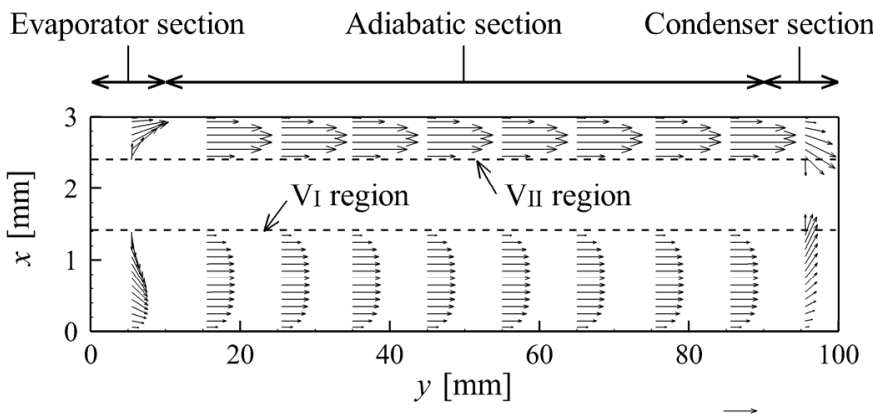

$20 \mathrm{~m} / \mathrm{s}$

(b) $\delta=0.4 \mathrm{~mm}$

Fig. 3 Vapor velocity distributions on the $x-y$ cross section at $z=0.2 \mathrm{~mm}(h=0.4 \mathrm{~mm})$.

$\rho_{v} h_{f g} u_{v, \mathrm{II}}=\rho_{l} h_{f g} u_{l}=-k_{e f f}\left(\frac{\partial T_{l}}{\partial x}\right)$

$v_{v, \mathrm{II}}=v_{l}=0, \quad w_{v, \mathrm{II}}=w_{l}=0$

Except for the abovementioned boundaries, the following fluid-flow and thermal boundary conditions were applied:

$u_{i}=0, \quad v_{i}=0, \quad w_{i}=0, \quad \frac{\partial T_{i}}{\partial n}=0$

where $n$ is the coordinate normal to the boundary surface. Moreover, because only second kind of boundary condition, i.e., temperature gradients were given on the outer surface of the heat pipe model, the temperature at $x=w_{v, \mathrm{I}}, y=l_{t} / 2$, and $z=h / 2$ was prescribed as the operating temperature, $T_{o}$. The control volume method and SIMPLE algorithm (Patankar, 1980) were employed for numerical calculation. The calculation was iterated until the changes in $u, v, w, p$ and $T$ values became smaller than $1.0 \%$.

Under the physical dimensions shown in Table 1, numerical results were obtained by changing $\delta$ as $0.0,0.2,0.4$, and $0.6 \mathrm{~mm}$. These values corresponded to $\left(w_{v, \mathrm{I}}, w_{v, \mathrm{II}}\right)=(1.0 \mathrm{~mm}, 1.0 \mathrm{~mm}),(1.2 \mathrm{~mm}, 0.8 \mathrm{~mm}),(1.4$ $\mathrm{mm}, 0.6 \mathrm{~mm})$, and $(1.6 \mathrm{~mm}, 0.4 \mathrm{~mm})$, respectively. Moreover, the height of the heat pipe model, $h$, was changed as $0.2,0.4$, and $0.8 \mathrm{~mm}$. Similar to the author's previous studies (Koito, 2019a; Koito, 2019b), sintered copper powder with the porosity of $\varepsilon=0.4$ and the permeability of $K=$ $9.00 \times 10^{-13} \mathrm{~m}^{2}$ was selected as the wick structure. Water was the working fluid of the heat pipe model. The $k_{\text {eff }}$ value was evaluated using Yagi-Kunii's equation (JAHP, 2001). Moreover, the numerical results

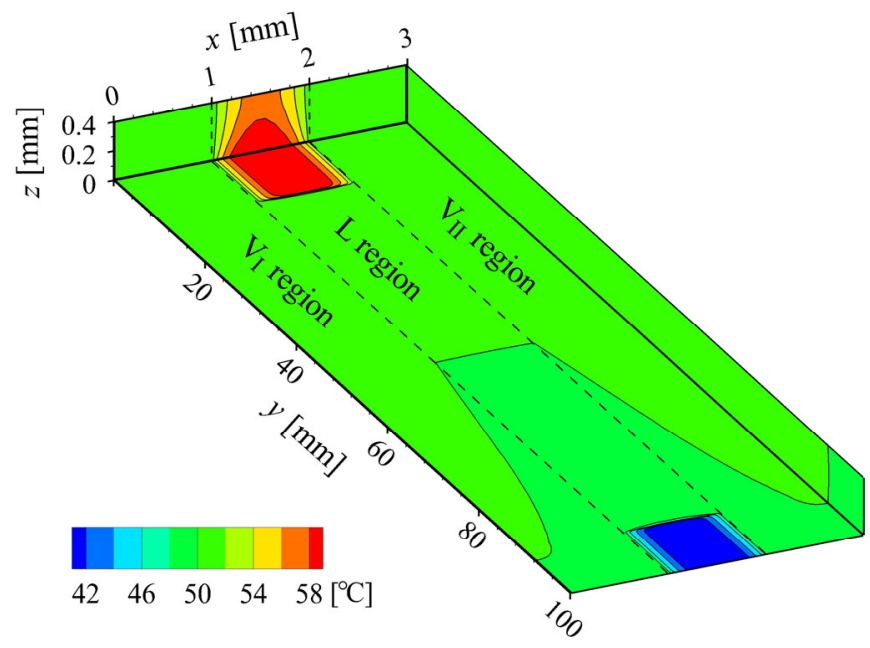

(a) $\delta=0 \mathrm{~mm}$

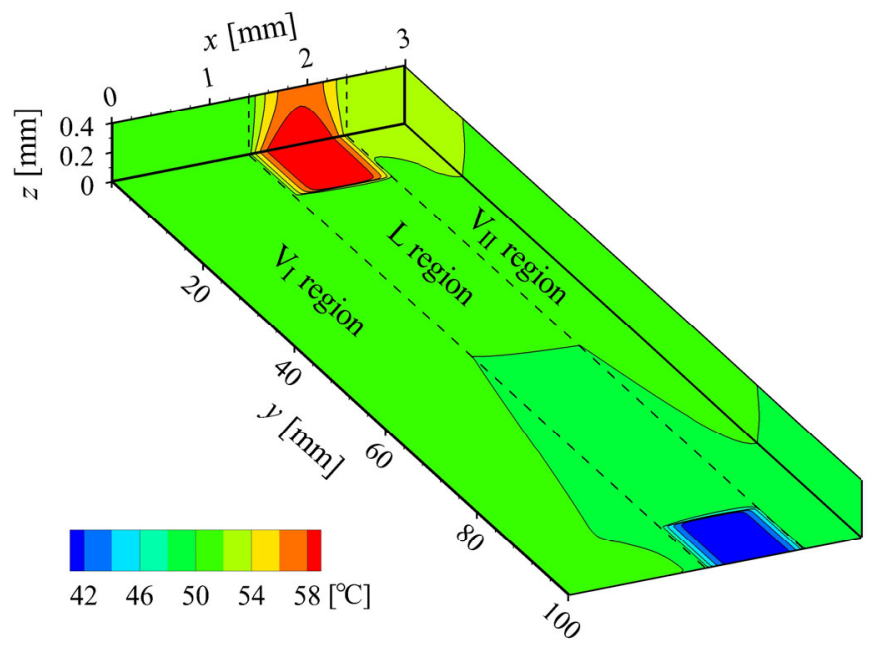

(b) $\delta=0.4 \mathrm{~mm}$

Fig. 4 Temperature distributions of the heat pipe model $(h=0.4 \mathrm{~mm})$.

were obtained when $w_{v, \mathrm{I}}=2.0$ and $w_{v, \mathrm{II}}=0 \mathrm{~mm}$. In this case, the deviation, $\delta$, was $1.0 \mathrm{~mm}$, and the wick structure was positioned at the side of the heat pipe model. $47 \times 99 \times 12(=x \times y \times z), 47 \times 99 \times 22$ and $47 \times 99 \times$ 42 grids were used when $h=0.2,0.4$ and $0.8 \mathrm{~mm}$, respectively. These numbers of grids were determined according to the result of grid size independence test described in the author's previous paper (Koito, 2019a)

\section{RESULTS AND DISCUSSION}

Figure 3 shows the vapor velocity distributions on the $x-y$ cross-section at $z=h / 2$. Figure 4 shows the temperature distributions of the heat pipe model. In these figures, two cases of (a) $\delta=0$ and (b) $\delta=0.4 \mathrm{~mm}$ are compared under the numerical condition of $h=0.4 \mathrm{~mm}$. The boundaries between the $\mathrm{V}_{\mathrm{I}}$ and $\mathrm{L}$ regions, and the $\mathrm{V}_{\mathrm{II}}$ and $\mathrm{L}$ regions, are indicated by dashed lines. In Fig. 3, concerning the vapor-flow characteristics from an evaporator to a condenser section, a difference was reported between the two cases of $\delta=0$ and $\delta=0.4 \mathrm{~mm}$. For $\delta=0 \mathrm{~mm}$, the vapor velocity 

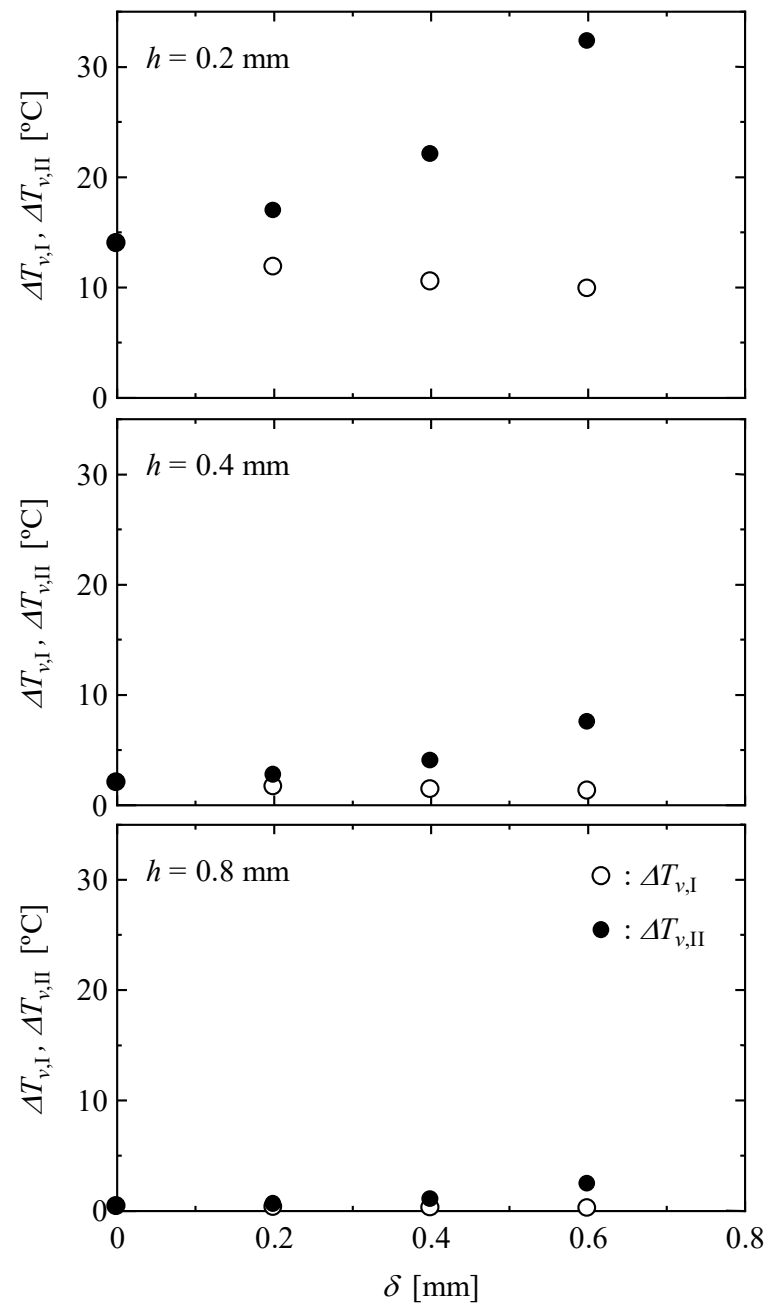

Fig. 5 Vapor temperature differences over the vapor regions.

distribution was axisymmetric at the center $(x=1.5 \mathrm{~mm})$ of the crosssection. For $\delta=0.4 \mathrm{~mm}$, however, the vapor velocity distribution was asymmetric, i.e., the vapor velocity in the $\mathrm{V}_{\text {II }}$ region was higher than that in the $V_{I}$ region because of the difference in the $x-z$ cross-sectional area between $V_{\text {I }}$ and $V_{\text {II }}$ regions: the cross-sectional area of the $V_{\text {II }}$ region was $57 \%$ lesser than the $\mathrm{V}_{\text {I }}$ region. Moreover, the vapor velocity in the $\mathrm{V}_{\text {II }}$ region for $\delta=0.4 \mathrm{~mm}$ was higher than that for $\delta=0 \mathrm{~mm}$, whereas the vapor velocity in the $\mathrm{V}_{\mathrm{I}}$ region for $\delta=0.4 \mathrm{~mm}$ was lower than that for the $\delta=0 \mathrm{~mm}$. Note that the drop in vapor pressure because of friction in the heat pipe model changed with the vapor velocity. Furthermore, as expressed by Eqs. (7) and (8), the temperatures at the vapor-liquid interfaces were determined by the local vapor pressures acting on these interfaces. This indicates that the vapor temperature distribution in the heat pipe model changed with the vapor velocity. Thus, as shown in Fig. 4 (b), because the vapor velocities in the $V_{\text {I }}$ and $V_{\text {II }}$ regions were different, asymmetric temperature distribution of the heat pipe model was obtained for $\delta=0.4 \mathrm{~mm}$. However, for $\delta=0 \mathrm{~mm}$, as shown in Fig. 4 (a), the temperature distribution was axisymmetric at the center $(x=1.5 \mathrm{~mm})$ of the heat pipe model. From the abovementioned results, the thermal-fluid transport characteristics of the heat pipe model changed with the deviation from the centered wick structure.

The vapor temperature differences over $\mathrm{V}_{\mathrm{I}}$ region, $\Delta T_{v, \mathrm{I}}$, and $\mathrm{V}_{\mathrm{II}}$ region, $\Delta T_{v, \mathrm{II}}$, were evaluated by the following equations:
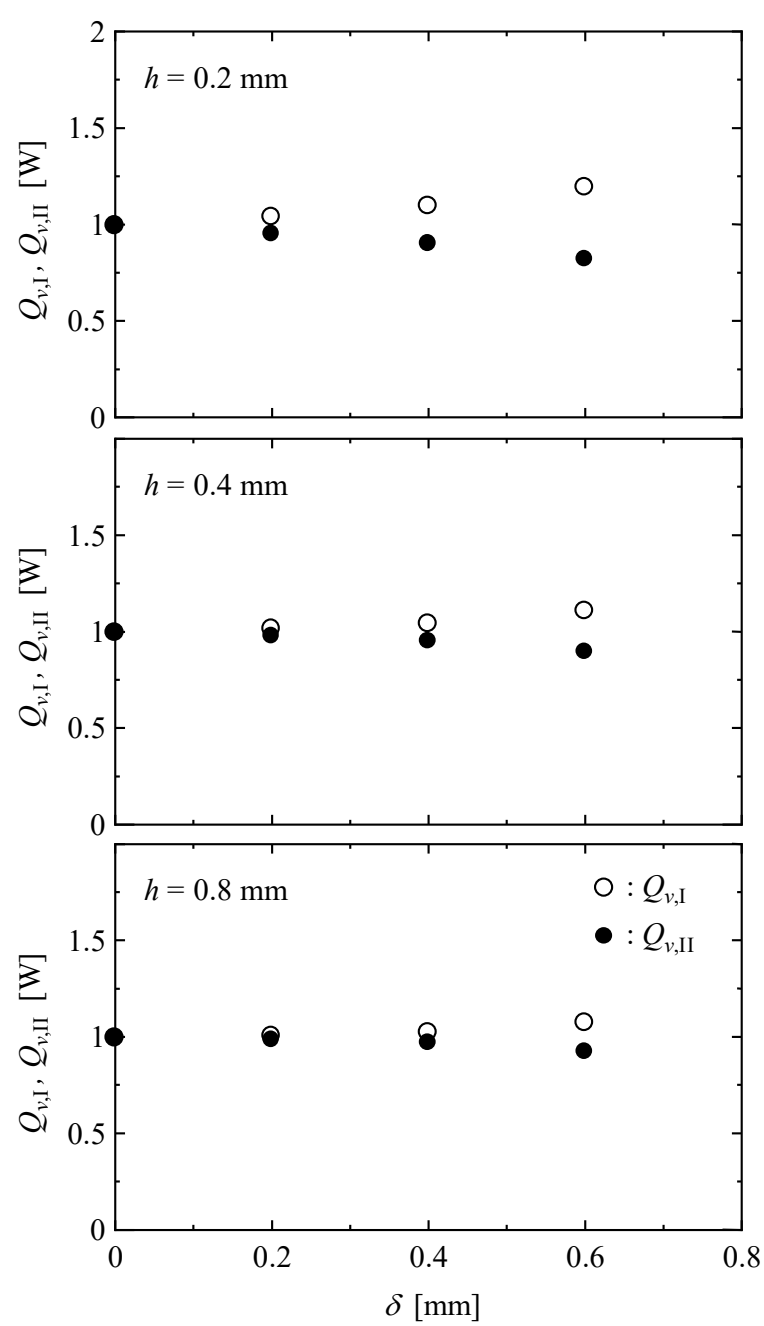

Fig. 6 Heat transport rates in the vapor regions.

$$
\begin{aligned}
& \Delta T_{v, \mathrm{I}}=T_{v, \mathrm{I}}\left(w_{v, \mathrm{I}}, 0, h / 2\right)-T_{v, \mathrm{I}}\left(w_{v, \mathrm{I}}, l_{t}, h / 2\right) \\
& \Delta T_{v, \mathrm{II}}=T_{v, \mathrm{II}}\left(w_{v, \mathrm{I}}+w_{l}, 0, h / 2\right)-T_{v, \mathrm{II}}\left(w_{v, \mathrm{I}}+w_{l}, l_{t}, h / 2\right)
\end{aligned}
$$

Figure 5 shows the $\Delta T_{v, \mathrm{I}}$ and $\Delta T_{v, \mathrm{II}}$ values with respect to $\delta$ for $h=$ $0.2,0.4$, and $0.8 \mathrm{~mm}$. As expected, $\Delta T_{v, \text { II }}$ increased with $\delta$ because of increase in the vapor velocity in the $\mathrm{V}_{\text {II }}$ region. The increase in $\Delta T_{v, \text { II }}$ with $\delta$ was less for $h=0.8 \mathrm{~mm}$, whereas it was very large for $h=0.2 \mathrm{~mm}$. The increase in $\Delta T_{v, \text { II }}$ caused an increase in the thermal resistance between the evaporator and condenser sections, resulting in a decrease in the thermal performance of heat pipe. The height of the vapor flow channel within the recent ultra-thin heat pipe was $0.2 \mathrm{~mm}$ (Shi et al., 2019). Thus, in the fabrication process of ultra-thin heat pipes, pinpoint accurate positioning of the wick structure is essential to avoid an unnecessary increase in thermal resistance.

The heat transport rates through $\mathrm{V}_{\mathrm{I}}$ region, $Q_{v, \mathrm{I}}$, and $\mathrm{V}_{\text {II }}$ region, $Q_{v, \mathrm{II}}$, were evaluated by the following equations:

$Q_{v, \mathrm{I}}=\int_{0}^{h} \int_{0}^{l_{t}} \rho_{v} h_{f g} \max \left[0,-u_{v, \mathrm{I}}\left(w_{v, \mathrm{I}}, y, z\right)\right] d y d z$ 


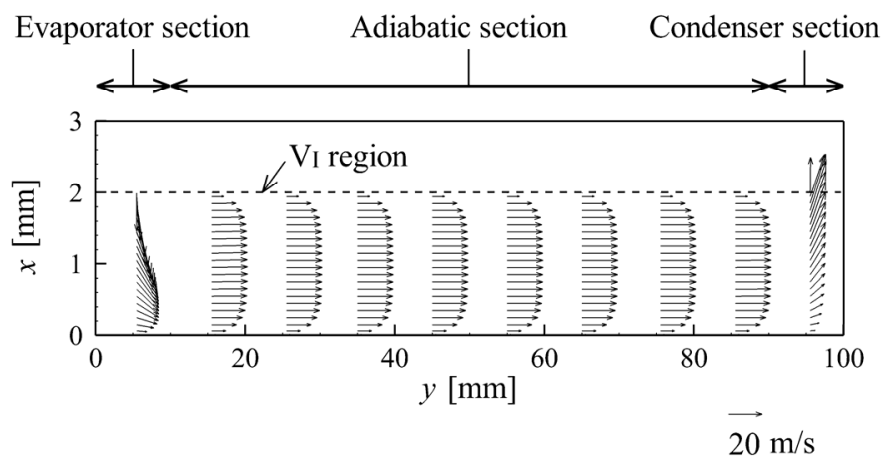

Fig. 7 Vapor velocity distribution on the $x-y$ cross section at $z=0.2 \mathrm{~mm}(\delta=1.0 \mathrm{~mm}, h=0.4 \mathrm{~mm})$.

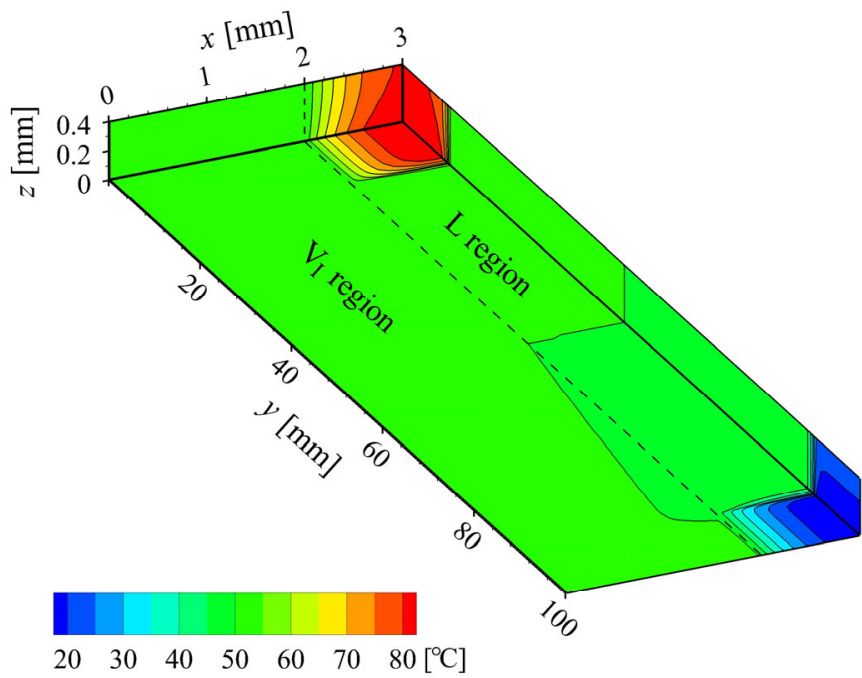

Fig. 8 Temperature distribution of the heat pipe model ( $\delta=1.0 \mathrm{~mm}, h=0.4 \mathrm{~mm})$.

$$
Q_{v, \mathrm{II}}=\int_{0}^{h} \int_{0}^{l_{t}} \rho_{v} h_{f g} \max \left[0, u_{v, \mathrm{II}}\left(w_{v, \mathrm{I}}+w_{l}, y, z\right)\right] d y d z
$$

where max [A, B] stands for the maximum of A and B. Because steadystate calculations were conducted in this study, the sum of $Q_{v, \text { I }}$ and $Q_{v, \text { II }}$ was essentially equal to the amount of heat applied to, or discharged from, the heat pipe model.

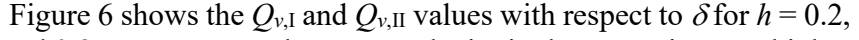
0.4 , and $0.8 \mathrm{~mm}$. Because the vapor velocity in the $\mathrm{V}_{\text {II }}$ region was higher than that in the $\mathrm{V}_{\text {I }}$ region, the vapor pressure at the evaporator section of the $V_{\text {II }}$ region was higher than that in the $V_{I}$ region. Thus, the boiling point of the working fluid at the evaporator section of the $\mathrm{V}_{\text {II }}$ region was higher than that in the VI region. Therefore, $Q_{v, \text { II }}$ was smaller than $Q_{v, \mathrm{I}}$, except for $\delta=0 \mathrm{~mm}$; moreover, the difference between $Q_{v, \mathrm{I}}$ and $Q_{v, \mathrm{II}}$ became larger with increase in $\delta$ and decrease in $h$. However, compared with the difference between $\Delta T_{v, \mathrm{I}}$ and $\Delta T_{v, \text { II }}$ (Fig. 5), such a large difference was not reported between $Q_{v, \mathrm{I}}$ and $Q_{v, \mathrm{II}}$.

Moreover, numerical analyses were conducted for the case in which the wick structure was positioned at the heat pipe model's side. In this calculation, only the $\mathrm{V}_{\mathrm{I}}$ region was considered with $w_{v, \mathrm{I}}=2.0, w_{l}=1.0$, and $w_{v, \text { II }}=0 \mathrm{~mm}$; the deviation, $\delta$, was $1.0 \mathrm{~mm}$. Rather than the thermal boundary condition of Eq. (8), the adiabatic condition: fourth equation of Eq. (11) was applied to the boundary at $x=w_{v, \mathrm{I}}+w_{l}$. Figures 7 and 8

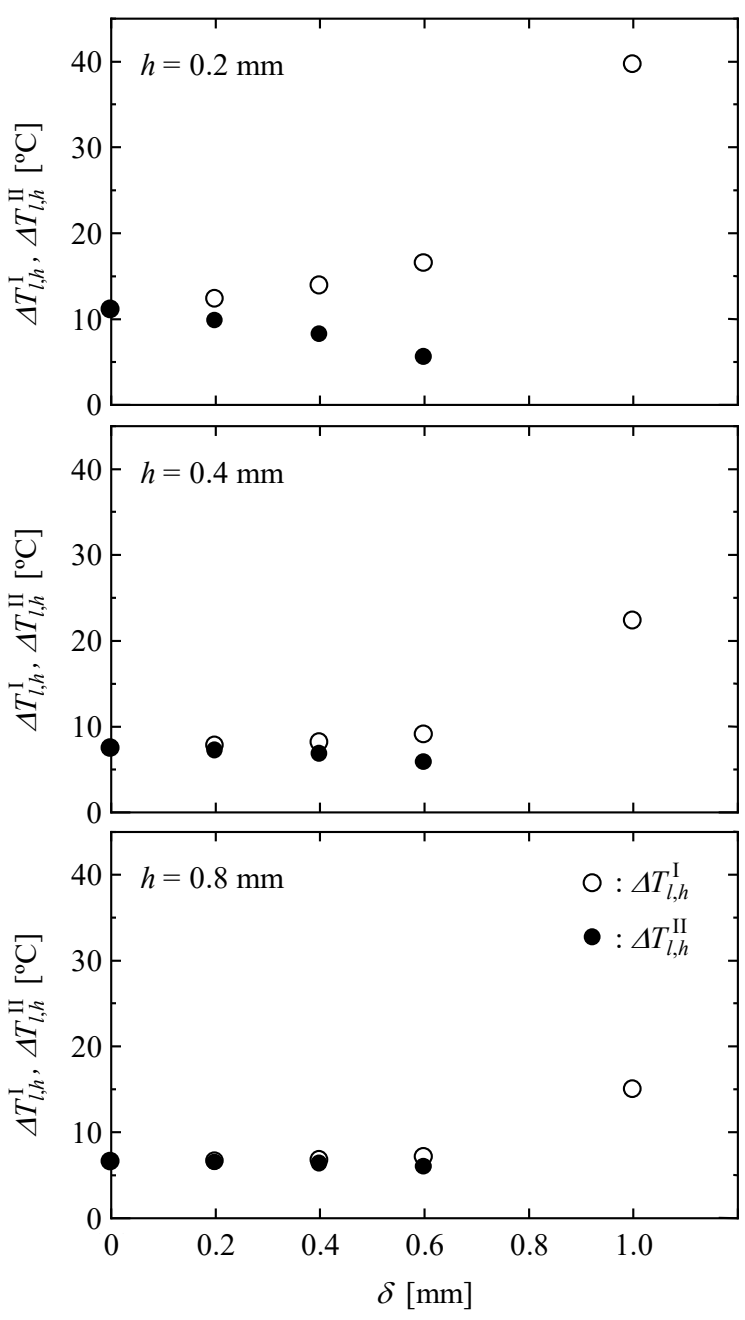

Fig. 9 Temperature differences in L region near the heated section.

show the vapor velocity distribution on the $x-y$ cross section at $z=h / 2$ and the temperature distribution of the heat pipe model, respectively, under the numerical conditions of $\delta=1.0$ and $h=0.4 \mathrm{~mm}$. The boundaries between the $\mathrm{V}_{\mathrm{I}}$ and $\mathrm{L}$ regions, as well as the $\mathrm{V}_{\text {II }}$ and $\mathrm{L}$ regions are indicated by dashed lines. By comparing Fig. 7 with Fig. 3 (a), the vapor velocity for $\delta=1.0 \mathrm{~mm}$ was slightly lower than that for the case of no deviation $(\delta=0 \mathrm{~mm})$ from the centered wick structure. Under $h=0.4$ $\mathrm{mm}$, the vapor temperature difference over $\mathrm{V}_{\mathrm{I}}$ region, $\Delta T_{v, \mathrm{I}}$, was $1.8^{\circ} \mathrm{C}$ for $\delta=1.0 \mathrm{~mm}$, whereas $\Delta T_{v, \mathrm{I}}=\Delta T_{v, \mathrm{II}}=2.0^{\circ} \mathrm{C}$ for $\delta=0 \mathrm{~mm}$. Because of the abovementioned lower vapor velocity, $\Delta T_{v, \mathrm{I}}$ for $\delta=1.0 \mathrm{~mm}$ was somewhat smaller than that for $\delta=0 \mathrm{~mm}$. By comparing Fig. 8 with Fig. 4 (a), the temperature gradients in the L region near the heated and cooled sections for $\delta=1.0 \mathrm{~mm}$ were much larger than those for the case of no deviation. Note that contour levels shown in Fig. 8 are different from those in Fig. 4 (a).

The temperature difference on the $\mathrm{V}_{\text {I }}$ side of the $\mathrm{L}$ region near the heated section, $\Delta T_{l, h}^{\mathrm{I}}$, was evaluated using the following equation:

$\Delta T_{l, h}^{\mathrm{I}}=\bar{T}_{l, h}-T_{v, \mathrm{I}}\left(w_{v, \mathrm{I}}, 0, h / 2\right)$

Moreover, except for $\delta=1.0 \mathrm{~mm}$, the temperature difference on the $\mathrm{V}_{\mathrm{II}}$ side of the $\mathrm{L}$ region near the heated section, $\Delta T_{l, h}^{\mathrm{II}}$, was evaluated by the following equation: 


$$
\Delta T_{l, h}^{\mathrm{II}}=\bar{T}_{l, h}-T_{v, \mathrm{II}}\left(w_{v, \mathrm{I}}+w_{l}, 0, h / 2\right)
$$

where $\bar{T}_{l, h}$ was the average temperature at the heated section. Using the average temperature, $\bar{T}_{l, c}$, at the cooled section, the temperature differences on the $\mathrm{V}_{\mathrm{I}}$ and $\mathrm{V}_{\mathrm{II}}$ sides, $\Delta T_{l, c}^{\mathrm{I}}$ and $\Delta T_{l, c}^{\mathrm{II}}$, of the $\mathrm{L}$ region near the cooled section were evaluated by the following equations:

$$
\begin{aligned}
& \Delta T_{l, c}^{\mathrm{I}}=\bar{T}_{l, c}-T_{v, \mathrm{I}}\left(w_{v, \mathrm{I}}, l_{t}, h / 2\right) \\
& \Delta T_{l, c}^{\mathrm{II}}=\bar{T}_{l, c}-T_{v, \mathrm{II}}\left(w_{v, \mathrm{I}}+w_{l}, l_{t}, h / 2\right)
\end{aligned}
$$

However, because the differences between $\Delta T_{l, h}^{\mathrm{I}}$ and $\Delta T_{l, c}^{\mathrm{I}}$, as well as $\Delta T_{l, h}^{\mathrm{II}}$ and $\Delta T_{l, c}^{\mathrm{II}}$, were $<0.6^{\circ} \mathrm{C}$, only $\Delta T_{l, h}^{\mathrm{I}}$ and $\Delta T_{l, h}^{\mathrm{II}}$ were used for the following discussion.

Figure 9 shows the $\Delta T_{l, h}^{\mathrm{I}}$ and $\Delta T_{l, h}^{\mathrm{II}}$ values with respect to $\delta$ for $h$ $=0.2,0.4$, and $0.8 \mathrm{~mm}$. Only $\Delta T_{l, h}^{\mathrm{I}}$ was shown for $\delta=1.0 \mathrm{~mm} . \Delta T_{l, h}^{\mathrm{I}}$ for $\delta=1.0 \mathrm{~mm}$ was considerably larger than the other temperature differences. This was because, for $\delta=1.0 \mathrm{~mm}$, only the $\mathrm{V}_{\text {I }}$ side of the vapor-liquid interface of the wick structure was used for evaporation. Except for $\delta=1.0 \mathrm{~mm}$, the evaporation occurred from both sides, i.e., the $\mathrm{V}_{\mathrm{I}}$ and $\mathrm{V}_{\mathrm{II}}$ sides of the wick structure. The increase in $\Delta T_{l, h}^{\mathrm{I}}$ caused a decrease in the thermal performance of the heat pipe. Thus, the centered wick structure was recommended for the ultra-thin heat pipes.

\section{CONCLUSIONS}

To investigate the fluid-flow and heat transfer characteristics of ultra-thin heat pipes in which the wick structure positioning had deviated from the center, numerical studies were conducted. The mathematical model of the heat pipe comprised the two vapor regions and the liquid-wick region between them. Numerical results were obtained by changing the deviation from the centered wick structure and the height of the model. Under the present numerical conditions, the results can be summarized as follows:

- $\quad$ Both vapor velocity and vapor temperature distributions of the heat pipe were changed by the deviation from the centered wick structure.

- $\quad$ One of the vapor regions was narrowed by the deviation. The vapor temperature difference over the narrowed vapor region increased with deviation. Moreover, when the height of the vapor region was $0.2 \mathrm{~mm}$, the increase in vapor temperature difference was conspicuous.

- When the wick structure was positioned at the side of the vapor region, the temperature differences in the liquid-wick region near the heated and cooled sections were very large.

- The increases in the abovementioned temperature differences caused a decrease in the thermal performance of the heat pipe. Therefore, for ultra-thin heat pipes, a centered wick structure is recommended. Moreover, accurate positioning of the wick structure is essential in the fabrication process of ultra-thin heat pipes.

\section{NOMENCLATURE}

$\begin{array}{ll}c_{p} & \text { specific heat at constant pressure }(\mathrm{J} /(\mathrm{kg} \cdot \mathrm{K})) \\ h & \text { height }(\mathrm{mm}, \mathrm{m}) \\ h_{f g} & \text { latent heat }(\mathrm{J} / \mathrm{kg}) \\ K & \text { permeability }\left(\mathrm{m}^{2}\right) \\ k & \text { thermal conductivity }(\mathrm{W} /(\mathrm{m} \cdot \mathrm{K})) \\ k_{\text {eff }} & \text { effective thermal conductivity }(\mathrm{W} /(\mathrm{m} \cdot \mathrm{K})) \\ l & \text { length }(\mathrm{mm}, \mathrm{m})\end{array}$

$n \quad$ coordinate normal to boundary surface (m)

$p \quad$ pressure $(\mathrm{Pa})$

$p_{\text {ref }} \quad$ reference pressure $(\mathrm{Pa})$

$Q \quad$ heat transport rate $(\mathrm{W})$

$q$ heat flux $\left(\mathrm{W} / \mathrm{cm}^{2}, \mathrm{~W} / \mathrm{m}^{2}\right)$

$R_{g} \quad$ gas constant $(\mathrm{J} /(\mathrm{kg} \cdot \mathrm{K}))$

$T \quad$ temperature $\left({ }^{\circ} \mathrm{C}\right)$

To operating temperature $\left({ }^{\circ} \mathrm{C}\right)$

$T_{\text {ref }} \quad$ reference temperature $\left({ }^{\circ} \mathrm{C}\right)$

$\bar{T} \quad$ average temperature $\left({ }^{\circ} \mathrm{C}\right)$

$u \quad$ velocity in $x$ direction $(\mathrm{m} / \mathrm{s})$

$\boldsymbol{V} \quad$ velocity vector $(=(u, v, w))(\mathrm{m} / \mathrm{s})$

$v \quad$ velocity in $y$ direction $(\mathrm{m} / \mathrm{s})$

$w \quad$ width $(\mathrm{mm}, \mathrm{m})$; velocity in $z$ direction $(\mathrm{m} / \mathrm{s})$

$x, y, z \quad$ three-dimensional coordinate $(\mathrm{mm}, \mathrm{m})$

Greek Symbols

$\delta \quad$ deviation (mm)

$\Delta T \quad$ temperature difference $\left({ }^{\circ} \mathrm{C}\right)$

$\varepsilon \quad$ porosity

$\mu \quad$ viscosity $(\mathrm{Pa} \cdot \mathrm{s})$

$\rho \quad$ density $\left(\mathrm{kg} / \mathrm{m}^{3}\right)$

Superscripts

I $\quad V_{\text {I region side }}$

II $\quad V_{\text {II }}$ region side

Subscripts

$c \quad$ cooled section

$h \quad$ heated section

$l \quad$ L region

$t \quad$ total

$v, \mathrm{I} \quad \mathrm{V}_{\mathrm{I}}$ region

$v$,II $\quad \mathrm{V}_{\text {II }}$ region

\section{REFERENCES}

Faghri, A., 2016, Heat Pipe Science and Technology, $2^{\text {nd }}$ ed., Global Digital Press.

Guo, H., Ji, X. and Xu, J., 2020, "Research and Development of Loop Heat Pipe - A Review," Frontiers in Heat and Mass Transfer, 14, 14. https://doi.org/10.5098/hmt.14.14

Japan Association for Heat Pipes (JAHP), 2001, Jitsuyou Heat Pipe, 2nd ed., Nikkan Kogyo Shimbun, Ltd., Tokyo (in Japanese).

Koito, Y., 2019a, "Numerical Analyses on Heat Transfer Characteristics of Ultra-thin Heat Pipes: Fundamental Studies with a Three-dimensional Thermal-fluid Model," Applied Thermal Engineering, 148, 430-437. https://doi.org/10.1016/j.applthermaleng.2018.10.119

Koito, Y., 2019b, "Numerical Analyses on Vapor Pressure Drop in a Centered-wick Ultra-thin Heat Pipe," Frontiers in Heat and Mass Transfer, 13, 26.

https://doi.org/10.5098/hmt.13.26

Li, J., Lv, L., Zhou, G. and Li, X., 2019, "Mechanism of a Microscale Flat Plate Heat Pipe with Extremely High Nominal Thermal Conductivity for Cooling High-end Smartphone Chips," Energy Conversion and Management, 201, 112202.

https://doi.org/10.1016/j.enconman.2019.112202

Liu, X., Xu, L., Wang, C. and Han, X., 2019, "Experimental Study on Thermo-hydrodynamic Characteristics in a Micro Oscillating Heat Pipe," Experimental Thermal and Fluid Science, 109, 109871. https://doi.org/10.1016/j.expthermflusci.2019.109871 
Luo, L., Huang, B., Bai, X., Cheng, Z. and Jian, Q., 2020, “Temperature Uniformity Improvement of a Proton Exchange Membrane Fuel Cell Stack with Ultra-thin Vapor Chambers," Applied Energy, 270, 115192. https://doi.org/10.1016/j.apenergy.2020.115192

Mochizuki, M. and Nguyen, T., 2019, "Review of Various Thin Heat Spreader Vapor Chamber Designs, Performance, Lifetime Reliability and Application," Frontiers in Heat and Mass Transfer, 13, 12. https://doi.org/10.5098/hmt.13.12

Naemsai, T., Kammuang-lue, N., Terdtoon, P. and Sakulchangsatjatai, P., 2019, "Numerical Model of Heat Transfer Characteristics for Sintered-grooved Wick Heat Pipes under Non-uniform Heat Loads," Applied Thermal Engineering, 148, 886-896.

https://doi.org/10.1016/j.applthermaleng.2018.10.058

Patankar, S.V., 1980, Numerical Heat Transfer and Fluid Flow, Hemisphere Pub. Corp., Washington, DC.

Sadeghinezhad, E., Mehrali, M., Rosen, M.A., Akhiani, A.R., Latibari, S.T., Mehrali, M. and Metselaar, H.S.C., 2016, "Experimental Investigation of the Effect of Graphene Nanofluids on Heat Pipe Thermal Performance," Applied Thermal Engineering, 100, 775-787.

http://dx.doi.org/10.1016/j.applthermaleng.2016.02.071

Shi, B., Zhang, H., Zhang, P. and Yan, L., 2019, "Performance Test of an Ultra-thin Flat Heat Pipe with a $0.2 \mathrm{~mm}$ Thick Vapor Chamber," Journal of Micromechanics and Microengineering, 29, 115019. https://doi.org/10.1088/1361-6439/ab42b3
Sobhan, C.B. and Peterson, G.P., 2019, "Investigations of Wire-bonded Micro Heat Pipes - A Review," Frontiers in Heat and Mass Transfer, 13,5 .

https://doi.org/10.5098/hmt.13.5

Sohel Murshed, S.M. and Nieto de Castro, C.A., 2017, "A Critical Review of Traditional and Emerging Techniques and Fluids for Electronics Cooling," Renewable and Sustainable Energy Reviews, 78, 821-833.

https://doi.org/10.1016/j.rser.2017.04.112

Tang, Y., Hong, S., Wang, S. and Deng, D., 2019, "Experimental Study on Thermal Performances of Ultra-thin Flattened Heat Pipes," International Journal of Heat and Mass Transfer, 134, 884-894. https://doi.org/10.1016/j.ijheatmasstransfer.2018.12.178

Tharayil, T., Asirvatham, L.G., Cassie, C.F.M. and Wongwises, S., 2017, "Performance of Cylindrical and Flattened Heat Pipes at Various Inclinations Including Repeatability in Anti-gravity - A Comparative Study," Applied Thermal Engineering, 122, 685-696.

http://dx.doi.org/10.1016/j.applthermaleng.2017.05.007

Zhong, G., Tang, Y., Ding, X., Rao, L., Chen, G., Tang, K., Yuan, W. and Li, Z., 2020, "Experimental Study of a Large-area Ultra-thin Flat Heat Pipe for Solar Collectors under Different Cooling Conditions," Renewable Energy, 149, 1032-1039.

https://doi.org/10.1016/j.renene.2019.10.093

Zhou, W., Li, Y., Chen, Z., Deng, L. and Gan, Y., 2019, "Effect of the Passage Area Ratio of Liquid to Vapor on an Ultra-thin Flattened Heat Pipe," Applied Thermal Engineering, 162, 114215. https://doi.org/10.1016/j.applthermaleng.2019.114215 